\title{
Characterization of water exchange and two-phase flow in porous gas diffusion materials by hydrogen-deuterium contrast neutron radiography
}

Ingo Manke, Christoph Hartnig, Nikolay Kardjilov, Matthias Messerschmidt, André Hilger, Markus Strobl, Werner Lehnert, and John Banhart

Citation: Appl. Phys. Lett. 92, 244101 (2008);

View online: https://doi.org/10.1063/1.2946664

View Table of Contents: http://aip.scitation.org/toc/apl/92/24

Published by the American Institute of Physics

\section{Articles you may be interested in}

Investigation of water evolution and transport in fuel cells with high resolution synchrotron x-ray radiography Applied Physics Letters 90, 174105 (2007); 10.1063/1.2731440

Quasi-in situ neutron tomography on polymer electrolyte membrane fuel cell stacks

Applied Physics Letters 90, 184101 (2007); 10.1063/1.2734171

Cross-sectional insight in the water evolution and transport in polymer electrolyte fuel cells Applied Physics Letters 92, 134106 (2008); 10.1063/1.2907485

High resolution imaging of 2D distribution of lithium in thin samples measured with multipixel detectors in sandwich geometry

Review of Scientific Instruments 88, 023706 (2017); 10.1063/1.4977217

Flexible sample environment for high resolution neutron imaging at high temperatures in controlled atmosphere Review of Scientific Instruments 86, 125109 (2015); 10.1063/1.4937615

Detection of water with high sensitivity to study polymer electrolyte fuel cell membranes using cold neutrons at high spatial resolution

Applied Physics Letters 102, 234102 (2013); 10.1063/1.4811246

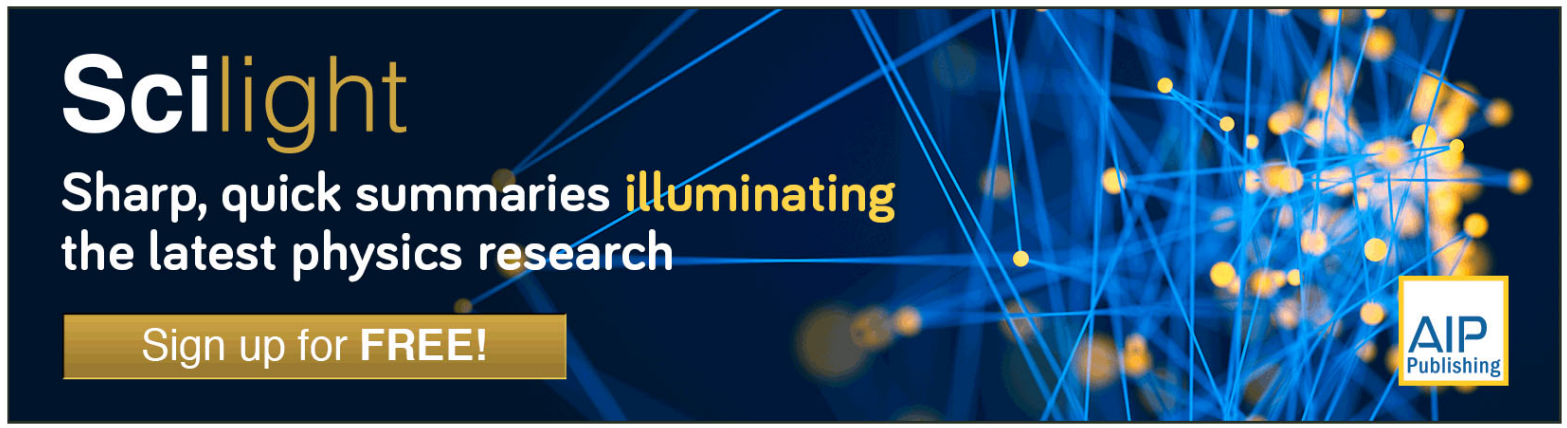




\title{
Characterization of water exchange and two-phase flow in porous gas diffusion materials by hydrogen-deuterium contrast neutron radiography
}

\author{
Ingo Manke, ${ }^{\text {a) }}$ Christoph Hartnig, Nikolay Kardjilov, Matthias Messerschmidt, André Hilger, \\ Markus Strobl, Werner Lehnert, and John Banhart \\ Hahn-Meitner Institute Berlin, Glienicker Str. 100, 14109 Berlin, Germany; Centre for Solar Energy \\ and Hydrogen Research (ZSW), 89081 Ulm, Germany
}

(Received 10 March 2008; accepted 28 May 2008; published online 17 June 2008)

\begin{abstract}
Liquid water exchange in two-phase flows within hydrophobic porous gas diffusion materials of polymer electrolyte membrane fuel cells was investigated spatially resolved with $\mathrm{H}-\mathrm{D}$ contrast neutron radiography. A commonly used one-phase model is sufficient to describe water exchange characteristics at low water production rates. At higher rates, however, a significantly higher exchange velocity is found than predicted by a simple model. A new model for the water transport is derived based on an eruptive mechanism guided by Haines jumps, which is supported by recent experimental findings and leads to a very good agreement with the experiments. () 2008 American Institute of Physics. [DOI: 10.1063/1.2946664]
\end{abstract}

Low temperature polymer electrolyte membrane fuel cells are among the most promising alternatives to conventional energy sources in mobile and stationary applications. ${ }^{1,2}$ In hydrogen polymer electrolyte membrane (PEM) fuel cells, liquid water plays a crucial role as, for example, water concentration and flow determine their efficiency and longevity. ${ }^{1}$

Water transport in fuel cell materials is commonly described by two-phase flow models, which take into account the complex transport interactions between liquid and gaseous phases, ${ }^{1,3-5}$ and numerous theoretical and experimental reports focusing on two-phase flow have been crucial for understanding the basics of water transport. ${ }^{3,4,6-16}$

In recent years, neutron radiography, ${ }^{10-13}$ magnetic resonance imaging, ${ }^{14}$ and (to a limited extent) x-ray imaging ${ }^{15-17}$ have been applied to visualize liquid water flow in fuel cells. However, until recently, it was not possible to quantify local water transport (exchange) rates inside fuel cell materials, i.e., the rates at which the accumulated water is exchanged by newly produced water from the cathode, especially under stationary conditions where the local water amount remains almost constant.

Here we report on measurements of the water exchange characteristics through GDLs of PEM fuel cells at operating conditions that provide insights into the actual water dynamics and the underlying transport mechanisms.

A single cell setup was used for the measurements. On the anodic and cathodic electrode, a threefold serpentine flow field with $1 \mathrm{~mm}$ wide channels and ribs and with an active area of $100 \mathrm{~cm}^{2}$ was used. The flow fields were machined in graphite composite plates with cooling flow fields on both electrodes to ensure a proper thermostatization. Gore Primea 5620 membrane electrode assemblies and SGL Carbon Sigracet 10 BB material were employed in the fuel cell construction. The utilization rates at the anode and cathode were $u_{A}=90 \%$ and $u_{C}=25 \%$. Ambient pressure was maintained at the media outlets. The temperature of the cell was $T$ $=60{ }^{\circ} \mathrm{C}$ and the cathodic gas stream was humidified $\left(\mathrm{H}_{2} \mathrm{O}\right)$ with a rather low dew point of $25{ }^{\circ} \mathrm{C}$ in order to limit water

\footnotetext{
${ }^{a)}$ Electronic mail: manke@hmi.de.
}

condensation from the gas stream to a negligible level. The radiography experiments were performed at the neutron tomography instrument CONRAD/V7 (HMI Berlin), which is described elsewhere. ${ }^{18}$

$\mathrm{H}-\mathrm{D}$ contrast neutron radiography is based on the different neutron attenuation strength of hydrogen and deuterium. Hydrogen interacts much stronger with neutrons than deuterium due to the high corresponding incoherent scattering length. Accordingly, light water $\left(\mathrm{H}_{2} \mathrm{O}\right)$ is a strong attenuator for neutron beams in comparison to heavy water $\left(\mathrm{D}_{2} \mathrm{O}\right)$, which is almost transparent. In order to exploit this fact, a PEM fuel cell was alternately fed with deuterium and hydrogen gas. Changes in the current density and the overall water transport dynamics of the fuel cell are negligible when it is operated with deuterium gas. After switching from hydrogen to deuterium, the deuterium gas is reduced to $\mathrm{D}_{2} \mathrm{O}$ at the catalyst and gradually replaces the liquid $\mathrm{H}_{2} \mathrm{O}$ in the GDL and in the flow-field channels. Thus the radiographic image contrast is a direct measure of the local $\mathrm{H}_{2} \mathrm{O}$ content in the fuel cell.

Figure 1 shows different normalized neutron radiographs of an operating PEM fuel cell before and after switching from hydrogen to deuterium gas. The liquid water distribution was quantified by normalizing to (dividing by) an image of the dry cell. Thereby, the pure water $\left(\mathrm{H}_{2} \mathrm{O}\right)$ distribution is revealed whereas other features of the fuel cell material or the flow-field structure are removed from the images. The varying local water thickness is displayed by different colors. Small clusters of liquid $\mathrm{H}_{2} \mathrm{O}$ in the GDL can be identified as green regions in Figure 1(a). The larger $\mathrm{H}_{2} \mathrm{O}$ amounts in the flow-field channels appear as red horizontal lines. About $45 \mathrm{~s}$ after switching from hydrogen to deuterium, some liquid $\mathrm{H}_{2} \mathrm{O}$ in the GDL is exchanged by $\mathrm{D}_{2} \mathrm{O}$ and the corresponding green areas become smaller [Figs. 1(b) and 1(c)]. After 24 min and $45 \mathrm{~s}$, almost all the $\mathrm{H}_{2} \mathrm{O}$ in the flow-field channels has been exchanged and hardly any $\mathrm{H}_{2} \mathrm{O}$ can be found in the GDL, i.e., maximum transmission comparable to that of the dry cell is achieved [Fig. 1(d)]. However, GDL and flowfield channels still contain some residual $\mathrm{H}_{2} \mathrm{O}$. After the gas feed is switched back to hydrogen the opposite effect is observed and the attenuation increases [Figs. 1(e) and 1(f)]. 

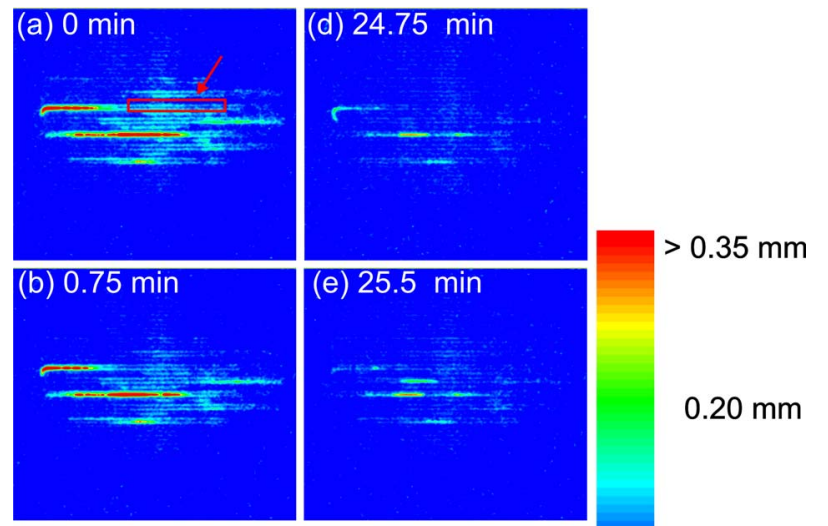

$0.20 \mathrm{~mm}$
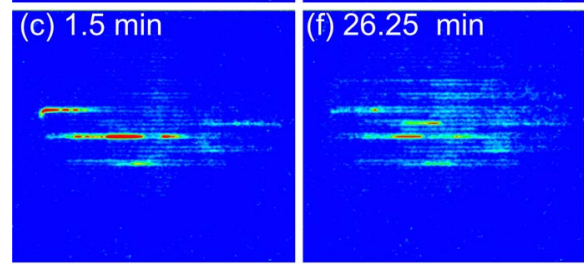

FIG. 1. (Color online) Neutron radiographs of a PEM fuel cell. After capturing the first image at $t=0 \mathrm{~min}$, the gas feed was switched from $\mathrm{H}_{2}$ to $\mathrm{D}_{2}$ and after 24.75 min. Back to $\mathrm{H}_{2}$. Red box: region of analysis for Fig. 2 .

For the area in Fig. 1(a) marked in red, the integral water amount was measured for two different operating conditions $\left(i_{0}=300 \mathrm{~mA} / \mathrm{cm}^{2}\right.$ and $\left.i_{0}=500 \mathrm{~mA} / \mathrm{cm}^{2}, u_{a}=90 \%, u_{k}=25 \%\right)$. This regime was chosen since here hardly any water can be found in the flow-field channels. Hence, only water accumulations in the GDL and the corresponding exchange characteristics are measured. The time development of the amount of light water after switching from $\mathrm{H}_{2}$ to $\mathrm{D}_{2}$ is shown in Fig. 2. At $i_{0}=300 \mathrm{~mA} / \mathrm{cm}^{2}$ an almost linear exchange is observed at the initial stage of the water exchange curve. In contrast, at $i_{0}=500 \mathrm{~mA} / \mathrm{cm}^{2}$, the exchange process shows a different behavior with a very fast initial decrease converging to a slower exchange rate for longer times.

In order to compare the exchange rate of liquid water and heavy water, we consider a commonly used one-phase convective model. ${ }^{19}$ The concentration decrease of $\mathrm{H}_{2} \mathrm{O}$ due to the production of $\mathrm{D}_{2} \mathrm{O}$ can be described by the following equation:

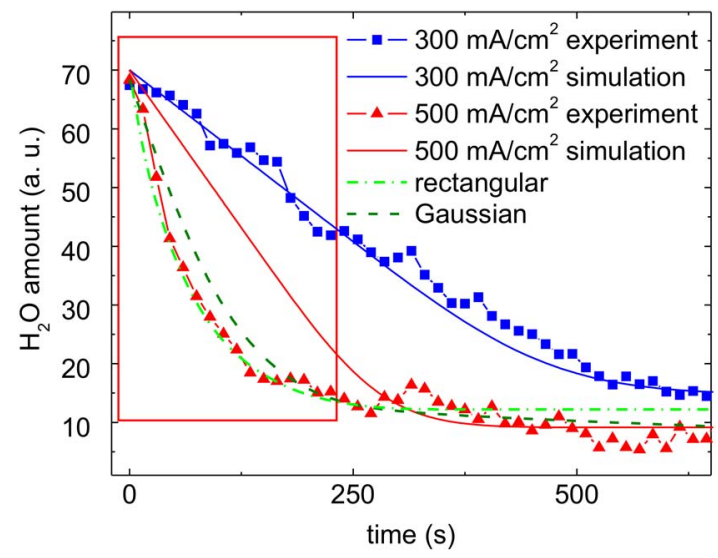

FIG. 2. (Color online) (a) Amount of liquid $\mathrm{H}_{2} \mathrm{O}$ in the red marked area of Fig. 1(a) after switching the gas feed from $\mathrm{H}_{2}$ to $\mathrm{D}_{2}$. (b) Initial phase after switching from $\mathrm{H}_{2}$ to $\mathrm{D}_{2}$, enlargement of the area marked in red in (a). a)
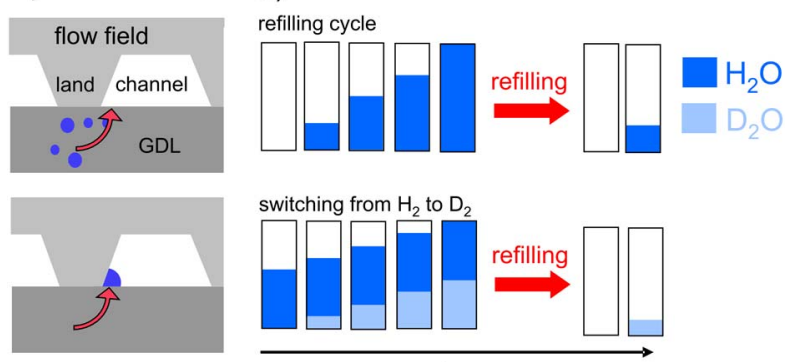

time $t$

FIG. 3. (Color online) (a) Principle of the eruptive water transport mechanism, water distribution in the GDL and the flow field before (top) and after eruption (bottom). (b) Filling process of the water transport channels in the GDL with $\mathrm{H}_{2}$ (top) and after switching from $\mathrm{H}_{2}$ to $\mathrm{D}_{2}$ (bottom).

$$
\frac{\partial c_{d}(t)}{\partial t}=-u \frac{\partial c_{d}(t)}{\partial x},
$$

where $x$ is the direction across the GDL, $c_{d}$ is the concentration of heavy water, and $u$ the constant velocity of the water flow. This equation is solved numerically by the differential equation,

$$
\frac{d c_{d}(t)}{d t}=-u \frac{c_{d}(t, x)-c_{d}(t, x-1)}{\Delta x} .
$$

The following parameters were chosen according to the literature: the diffusion speed $\mathrm{u}=5.365 \times 10^{-7} \mathrm{~m} / \mathrm{s}$, porosity $\varepsilon=0.7, c_{d}(x=0, t)=55.2 \mathrm{~mol} / 1$ (boundary condition), and $c_{d}(x, 0)=0$ (starting condition). ${ }^{19}$ The results correspond to a GDL thickness of $200 \mu \mathrm{m}$ and 20 discretization elements were taken into account. All the other parameters are constants such as the Faraday constant or the concentration of light and heavy water. Concerning the choice of the parameters, only the thickness of the GDL as well as the porosity have been taken in order to resemble a standard media. The diffusion velocity is calculated based on the current density, which in turn is a parameter that can be freely chosen (within reasonable sizes).

Equation (2) was solved for two different current densities: $i_{0}=300 \mathrm{~mA} / \mathrm{cm}^{2}$ and $i_{0}=500 \mathrm{~mA} / \mathrm{cm}^{2}$. Results for the time dependent $\mathrm{H}_{2} \mathrm{O}$ amounts are shown in Fig. 2 (solid lines). At $i_{0}=300 \mathrm{~mA} / \mathrm{cm}^{2}$, the calculated $\mathrm{H}_{2} \mathrm{O}$ concentrations are in very good agreement with the experimental data (blue lines). However, at higher current densities ( $i_{0}$ $=500 \mathrm{~mA} / \mathrm{cm}^{2}$ ) the measured exchange rate is much faster than predicted by the one-phase convective model (red lines). The particular shape of the experimentally measured curve with an initial fast decay cannot be reproduced by variation of the parameters introduced above.

In order to describe exchange characteristics at increased current densities, we introduce a model based on a water transport mechanism that was recently found in ex situ experiments by Litster et al. (see Ref. 8), which is in good agreement with in situ synchrotron radiography measurements on PEM fuel cells. ${ }^{17}$ Water transport is supposed to occur through "transport channels" in the GDL in discrete steps of ejection, which are best described by Haines jumps (bursts) and correlated choke-off effects. ${ }^{5,20}$ Such a water transport channel consists of several interconnected GDL pores plus at least one constriction close to the gas transport channel (Fig. 3). The channel is continuously filled with liq- 
uid water due to convection or precipitation up to a certain level, where the driving pressure is high enough to push the water through the constriction. This yields a spontaneous ejection of the water into the flow-field channel where it forms a droplet that is later evaporated or moved away by the gas or water flow in the channel. The rate of channel filling depends strongly on the operating conditions. Velocity and pressure threshold for the eruptions remain almost constant under stationary conditions with a specific repetition time $T$ for the eruption. ${ }^{17}$

The transport channels could be characterized by a period time $T$ and a corresponding phase (that describes the filling level at the D-H switching time). Furthermore we assume that the water volume capacity of the channels is equally distributed for channels with period times between $T_{1}$ and $T_{2}$ (box distribution).

After some calculations, it can be shown that the remaining amount of $\mathrm{H}_{2} \mathrm{O}$ at a specific location at time $t(0 \leqslant t$ $\leqslant T_{2}$ ) is given by

$$
\begin{aligned}
W^{\text {all }}(t) & =\frac{W_{0}}{T_{2}-T_{1}}\left[\left(\frac{t^{2}}{t^{\prime}}-\frac{t^{2}}{T_{2}}\right)+2 t \ln \left(\frac{t^{\prime}}{T_{2}}\right)+T_{2}-t^{\prime}\right] \\
\text { where } & =\left\{\begin{array}{l}
T_{1}, 0 \leqslant t \leqslant T_{1} \\
t, T_{1} \leqslant t \leqslant T_{2}
\end{array} .\right.
\end{aligned}
$$

$W_{0}$ is the overall water amount of all transport channel at $t=0$ and $1 / T_{2}-T_{1}$ was added for normalization. At $t \geqslant T_{2}$, all $\mathrm{H}_{2} \mathrm{O}$ has been exchanged by $\mathrm{D}_{2} \mathrm{O}$ and $W^{\text {all }}(t)=0$.

Alternatively the box distribution can be exchanged with a Gaussian distribution with its mean value around $T_{0}$ and a width specified by $\sigma_{T}$ :

$$
G(t)=\exp \left[\frac{1}{2}\left(\frac{T-T_{0}}{\sigma_{T}}\right)^{2}\right] .
$$

The result for the best fit with this approach is shown in Fig. 2. In the following discussion, we refer to the "box distribution fit" as fit 1, while fit 2 is based on a Gaussian distribution of the water capacities.

As can be derived from Fig. 2, both approaches (fit 1 and fit 2) are in good agreement with the experiments. The initial fast decay at low $T$ values is very well reproduced. The fitting parameters are $T_{1}=30 \mathrm{~s}$ and $T_{2}=360 \mathrm{~s}$ for fit 1 and $T_{0}$ $=30 \mathrm{~s}$ and $\sigma_{T}=200 \mathrm{~s}$ for fit 2 , respectively. These values are comparable to recent findings mentioned above. ${ }^{17}$

However, slight deviations can be found between both approaches. In contrast to fit 1 , the Gaussian approach of fit 2 shows slight deviations from the experimental data at early times. This can be explained by the rather weak contribution of fast transport channels for low $T$ values due to the decay of the Gaussian distribution. The experimental data indicates that these fast transport channels play a very important role in the overall transport process and are not sufficiently described by fit 2 . On the other hand, the Gaussian approach fits better than fit 1 for times $>200 \mathrm{~s}$, presumably because it also includes a few very slow processes with high $T$ values, which are completely neglected by fit 1 . The slow processes can be attributed either to slow eruptive transport events that were also found experimentally ${ }^{17}$ or (possibly in addition to that) to other slow water exchange mechanisms where a more complex interaction between gas phase and liquid phase plays a role. In the simplest case, water could be trapped in pores which do not allow for any transport (e.g., dead end pores or channels with very pronounced constrictions). In this case, water might be slowly exchanged by evaporation and condensation, i.e., no water transport in the liquid phase (convection) occurs.

In conclusion, H-D contrast neutron radiography opens up the way for imaging and characterizing two-phase flow phenomena in porous media of fuel cells that are inaccessible by other methods. Water exchange rates were measured under stationary conditions providing insights into the transport dynamics. At low water production rates, a well-known onephase convective model is sufficient to describe the exchange characteristics. However, we have found much faster water exchange than expected at increased current densities. In this case, we could describe the exchange behavior by an eruptive transport mechanism based on bursts-similar to Haines jumps- that also explains other experiments. ${ }^{8,17}$ The proposed fit model is in very good agreement with the experimental results obtained by $\mathrm{H}-\mathrm{D}$ contrast neutron radiography. The corresponding time constants and distributions of periods agree with the recent literature. The fit model can be used for further development of more sophisticated twophase flow models in future.

The research activities were partly funded by the German Federal Ministry for Education and Science (BMBF) under Grant No. 03SF0324A and 03SF0324F.

${ }^{1}$ C. Y. Wang, in Handbook of Fuel Cells-Fundamentals, Technology and Applications, edited by W. Vielstich, A. Lamm, and H. A. Gasteiger (Wiley, Chichester, 2003), Vol. 3, pp. 337-347.

${ }^{2}$ L. Carrette, K. A. Friedrich, and U. Stimming, Fuel Cells 1, 5 (2001).

${ }^{3}$ U. Pasaogullari and C. Y. Wang, J. Electrochem. Soc. 152, 380 (2005).

${ }^{4}$ C. Ziegler, H. M. Yu, and J. O. Schumacher, J. Electrochem. Soc. 152, 1555 (2005).

${ }^{5}$ B. Berkowitz and R. P. Ewing, Surv. Geophys. 19, 23 (1998).

${ }^{6}$ C.-Y. Wang and P. Cheng, Int. J. Heat Mass Transfer 39, 3607 (1996).

${ }^{7}$ G. Lin, W. He, and T. Van Nguyen, J. Electrochem. Soc. 151, 1999 (2004).

${ }^{8}$ S. Litster, D. Sinton, and N. Djilali, J. Power Sources 154, 95 (2006).

${ }^{9}$ A. A. Kulikovsky, T. Wüster, A. Egmen, and D. Stolten, J. Electrochem. Soc. 152, 1290 (2005).

${ }^{10}$ M. A. Hickner, N. P. Siegel, K. S. Chen, D. S. Hussey, D. L. Jacobson, and M. Arif, J. Electrochem. Soc. 155, 427 (2008).

${ }^{11}$ P. Boillat, D. Kramer, B. C. Seyfang, G. Frei, E. Lehmann, G. G. Scherer, A. Wokaun, Y. Ichikawa, Y. Tasaki, and K. Shinohara, Electrochem. Commun. 10, 546 (2008)

${ }^{12}$ I. Manke, C. Hartnig, N. Kardjilov, M. Grünerbel, A. Hilger, J. Kaczerowski, W. Treimer, M. Strobl, W. Lehnert, and J. Banhart, Appl. Phys. Lett. 90, 184101 (2007).

${ }^{13}$ J. P. Owejan, T. A. Trabold, D. L. Jacobson, D. R. Baker, D. S. Hussey, and M. Arif, Int. J. Heat Mass Transfer 49, 4721 (2006).

${ }^{14}$ K. W. Feindel, S. H. Bergens, and R. E. Wasylishen, J. Am. Chem. Soc. 128, 14192 (2006).

${ }^{15}$ P. K. Sinha, P. P. Mukherjee, and C. Y. Wang, J. Mater. Chem. 17, 3089 (2007).

${ }^{16}$ C. Hartnig, I. Manke, R. Kuhn, N. Kardjilov, J. Banhart, and W. Lehnert, Appl. Phys. Lett. 92, 134106 (2008).

${ }^{17}$ I. Manke, C. Hartnig, M. Grünerbel, W. Lehnert, N. Kardjilov, A. Haibel, H. Hilger, H. Riesemeier, and J. Banhart, Appl. Phys. Lett. 90, 174105 (2007).

${ }^{18}$ A. Hilger, N. Kardjilov, M. Strobl, W. Treimer, and J. Banhart, Physica B 385-386, 1213 (2006).

${ }^{19}$ J. H. Ferziger and M. Peric, Computational Methods for Fluid Dynamics, 3rd ed. (Springer, Berlin, 2002).

${ }^{20}$ W. B. Haines, J. Agric. Sci. 20, 97 (1930). 